\title{
Effect of Calcined Colemanite Addition on the Rheological Behaviour of Porcelain Suspension
}

\begin{abstract}
Y. ÖZdEMiR, S. AKPINAR*, S. ABBAK AND A. EvCIN
Afyon Kocatepe University, Material Science and Engineering Department, Afyonkarahisar, Turkey

A standard composition for hard porcelain production was prepared by mixing $50 \mathrm{wt} \%$ kaolin, $25 \mathrm{wt} \%$ potassium feldspar and $25 \mathrm{wt} \%$ quartz. Calcined colemanite powders were added to the porcelain formulation by replacing the potassium feldspar up to $5 \mathrm{wt} \%$ to explore its effect on the rheological behaviour of porcelain slip casting. A rheological study has been carried out in order to optimize the processing of the slip casting by using a rotational stress-controlled rheometer. The measurements were performed at constant temperature $\left(25^{\circ} \mathrm{C}\right) \mathrm{using}$ a parallel plate configuration. Sweep measurements were then conducted in the shear rates ranging from about $0.1-1000 \mathrm{~s}^{-1}$. The stability of the suspensions with ammonium polyacrylate (Darvan $821 \mathrm{~A}$ ) was determined in order to select the suitable dispersant amount. In order to achieve casting of acceptable characteristics on a plaster of Paris mould, the slurry should have the appropriate thixotropic or shear-thinning behaviours. Therefore, the same favourable thixotropic behaviour of slurries of different amount of calcined colemanite powders, the solid contents of the slurries have been optimised.
\end{abstract}

DOI: 10.12693/APhysPolA.132.825

PACS/topics: rheology, colemanite, slip casting

\section{Introduction}

Rheology is the study of the viscous behaviours of fluids, suspensions, and forming bodies that occur over the full range of applied shear conditions. When a fluid is characterized by a single, constant viscosity over the whole range of shear rates, it is known as a Newtonian fluid. Fluids that do not exhibit constant viscosity as shear rates vary are called non-Newtonian fluids, since almost all ceramic production bodies are multi-phase, complex suspensions which exhibit non-Newtonian rheologies [1,2].

A typical ceramic suspension is a mixture of fine powders with fluids in the presence of minor additions of a variety of inorganic and organic additives. The major contributors to the rheological behaviour of suspensions are the properties and characteristics of the powders and of the carrier fluids. The additives, which usually comprise a fraction of a percent (by mass) of the powder in a suspension, modify and control the interfacial properties and interactions between the powders and the fluid, and thereby also modify and control the rheological properties of the suspensions [1].

There are several categories of effects in which the powder fractions of suspensions play major roles in the control of rheological properties. The solids contents of suspensions, the particle-size distributions of the powders, the properties of the powder constituents, the flocculation states of suspensions, and the nature and intensity of particle/particle collisions must each be considered [1]

In suspensions, the percentage of solids has a major effect on rheological properties. When solids contents are low, fluid viscosities increase slowly as solids are added.

*corresponding author; e-mail: akpinar@aku.edu.tr
At low solids contents when the volume concentration of particles is small, suspension viscosity closely approximates the carrier fluid viscosity. In such cases, the fluid viscosity dominates to control suspension viscosity. As solids contents rise, suspension properties quickly deviate from their similarities to the properties of the carrier fluid. At high solids contents, the particulate fraction has the major controlling effect on suspension viscosities. Each suspension will have an upper solids content limit, beyond which flow ceases. This occurs when a continuous network of touching particles spans the bulk volume of the suspension and particles are no longer free to move within the suspension [1].

The nature of the powders and their surface properties also affect the rheological properties of suspensions. This is especially the case when solids contents are sufficiently high that particles collide frequently during suspension flow. When surfaces are relatively smooth, particles can slide easily against one another. When particle surfaces are rough and tortuous, particle/particle friction during collisions can hinder flow and markedly increase suspension viscosities [1].

Chemical additives are routinely used to deflocculate suspensions to reduce their viscosities, or to flocculate suspensions to increase their viscosities. Within suspensions that are highly deflocculated, all particles will strongly repel one another. This happens when their surfaces are electrostatically highly charged either positive or negative. When suspensions are highly flocculated, the particles' electrostatic surface charges will be near zero. This usually occurs when multivalent cations such as $\mathrm{Ca}^{++}, \mathrm{Mg}^{++}$, or $\mathrm{Al}^{+++}$in the form of soluble and partially-soluble salts of $\mathrm{Cl}^{-}, \mathrm{SO}_{4}^{-}$, and $\mathrm{CO}_{3}^{--}$, for example, are added to the suspensions [1].

Compared with conventional dry pressing technologies, slip casting has great advantages in producing homogeneous green bodies with various geometric shapes, espe- 
cially in multi-component systems. The homogenisation and the rheological behaviour of the suspensions have been shown to play a significant role on the slip casting processing, and in turn, on the microstructure and properties of the final products. A well dispersed slurry can be obtained by choosing an appropriate dispersant, an optimal concentration of this dispersant and a proper $\mathrm{pH}$ value $[3-5]$.

Boron oxide-bearing minerals can technologically be considered as important alternative raw materials since they have a glass-forming character and have been used in the ceramic industry to reduce the melting point, lower the viscosity and decrease the thermal expansion of the glass phase and therefore raise its heat-resistance, and increase the mechanical strength and chemical stability of the materials [6-9]. Presently, borates, especially colemanite, find a wide variety of applications in industry [10-12]. Colemanite is a hydrated calcium borate $\mathrm{Ca}_{2} \mathrm{~B}_{6} \mathrm{O}_{11} \cdot 5 \mathrm{H}_{2} \mathrm{O}$, whose crystalline structure contains complex chains of tetrahedral $\mathrm{B}(\mathrm{O}, \mathrm{OH})_{4}$ and triangles $\mathrm{BO}_{3}$, bound into a triangular structure via the ions $\mathrm{Ca}^{2+}$ and buffer molecules $\mathrm{H}_{2} \mathrm{O}[6]$. Colemanite decrepitates as a result of the sudden release of confined water vapour within micropores during thermal treatment [13]. The direct use of colemanite is problematic for some industrial applications, e.g., in glasses and ceramics due to the decomposition of the colemanite mineral would cause body deformation when sintered especially in a fast firing condition. Therefore, removing impurities and crystal water of colemanite must undergo heat treatment before use [14].

The purpose of this research is to investigate the possible use of calcined colemanite, was selected as processing aids, in partial substitution of potassium feldspar, for hard porcelain production. In accordance with these purposes, the study presents the initial results of calcined colemanite on the rheological behaviour of hard porcelain based ceramic suspensions with different solid loadings.

\section{Experimental procedure}

The raw materials used for preparation porcelain composition in the present investigation were kaolin $\left(d_{50}=\right.$ $9.822 \mu \mathrm{m}$ and specific surface area $11.804 \mathrm{~m}^{2} / \mathrm{g}$ ), quartz $\left(d_{50}=25.690 \mu \mathrm{m}\right.$ and specific surface area $\left.0.588 \mathrm{~m}^{2} / \mathrm{g}\right)$, potassium feldspar $\left(d_{50}=18.434 \mu \mathrm{m}\right.$ and specific surface area $0.961 \mathrm{~m}^{2} / \mathrm{g}$ ) and ground colemanite under $75 \mu \mathrm{m}$ (specific surface area $6.48 \mathrm{~m}^{2} / \mathrm{g}$ ) provided by Ceramic Companies in Turkey.

The heat treatment for the removing impurities and crystal water of colemanite was performed in a modified domestic microwave oven by using silicon carbide susceptors and porous fibreboard box high power level (539 W) for $10 \mathrm{~min}$. The temperature of the samples was monitored as $450{ }^{\circ} \mathrm{C}$ using a thermocouple (TP-01 Type K). Specific surface area of colemanite powders after calcination was found to be $3.51 \mathrm{~m}^{2} / \mathrm{g}$.

A standard composition for hard porcelain production was prepared by mixing $50 \mathrm{wt} \%$ kaolin, $25 \mathrm{wt} \%$ potas- sium feldspar, and 25 wt\% quartz. Typically, potassium feldspar is used as fluxing agent in the industrial manufacture of hard porcelain stoneware. However, in the present study, colemanite (calcium borate) was chosen as another fluxing agent partially replacing potassium feldspar since fully crystallized alkali containing raw materials such as feldspars have a lower fusibility due to the higher energy threshold for crystal network destruction.

The standard composition of triaxial porcelain, defined as PC0 (0 wt\% of colemanite), was the formulation reference. Five additional formulations, with increasing amounts of colemanite (with respect to $\mathrm{PC} 0$ ), designated $\mathrm{PC} 1$ to PC5 (C and the number refers to the colemanite and wt\% of its in batch, respectively), were prepared in laboratory conditions via mixing by wet route. The batch compositions of bodies with additives are given in Table I.

Compositions [wt\%] of powder mixtures.

TABLE I

\begin{tabular}{l|c|c|c|c|c|c}
\hline \hline & PC0 & PC1 & PC2 & PC3 & PC4 & PC5 \\
\hline kaolin & 50 & 50 & 50 & 50 & 50 & 50 \\
quartz & 25 & 25 & 25 & 25 & 25 & 25 \\
K-feldspar & 25 & 24 & 23 & 22 & 21 & 20 \\
calcined colemanite & 0 & 1 & 2 & 3 & 4 & 5
\end{tabular}

Batches (250 g each) were prepared by mixing the constituents with distilled water and dispersing agent for $15 \mathrm{~min}$ on a magnetic stirrer at $750 \mathrm{rpm}$. Up to $70 \mathrm{wt} \%$ solid loadings were determined by using different amounts of an ammonium polyacrylate (Darvan 821A) in the range of $0.2-1 \mathrm{wt} \%$ (based on the solid content).

A rheological study has been carried out in order to optimize the rheological behaviour of the porcelain slurries by using a rotational stress-controlled rheometer (Antoon Paar-MCR 102 model rheometer). The measurements were performed at constant temperature $\left(25^{\circ} \mathrm{C}\right)$ using a plate and plate configuration (PP50; $50 \mathrm{~mm}$ diameter of each plate). Sweep measurements were then conducted in the shear rates ranging from about $1-1000 \mathrm{~s}^{-1}$.

The evolution of the rheological properties of the suspensions with different solid loadings and dispersant concentrations ammonium polyacrylate (Darvan 821A) was determined in order to select the highest solid content and suitable dispersant concentration as a function of solid loadings. However, effect of calcined colemanite on the rheological properties of the suspensions was also investigated. In order to the same favourable thixotropic behaviour of slurries of different amount of calcined colemanite powders, the solid contents of the slurries have been optimised.

\section{Results and discussion}

The evolution of the rheological properties of the suspensions containing 50,60, 65, and $70 \mathrm{wt} \%$ solids with different dispersant concentrations is reported in Figs. 14 , respectively. 


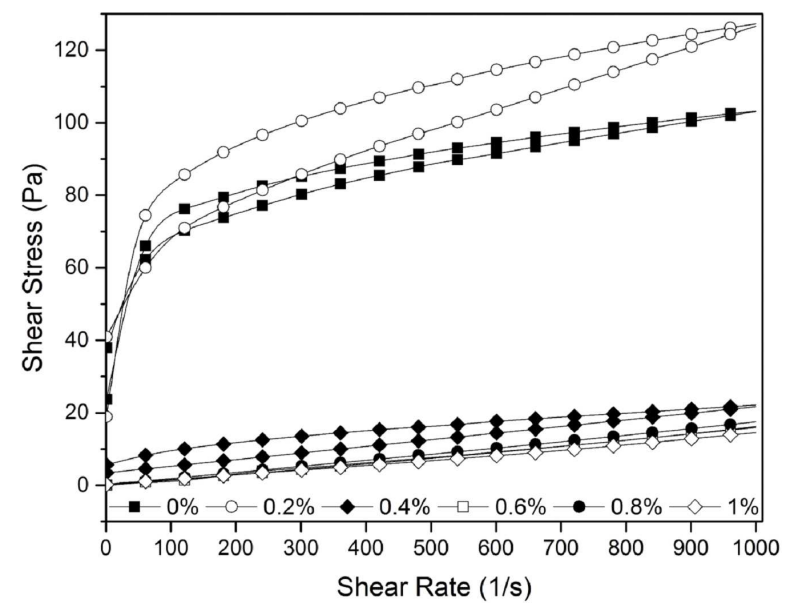

Fig. 1. The rheological flow curves of suspensions with $50 \mathrm{wt} \%$ solid loading.

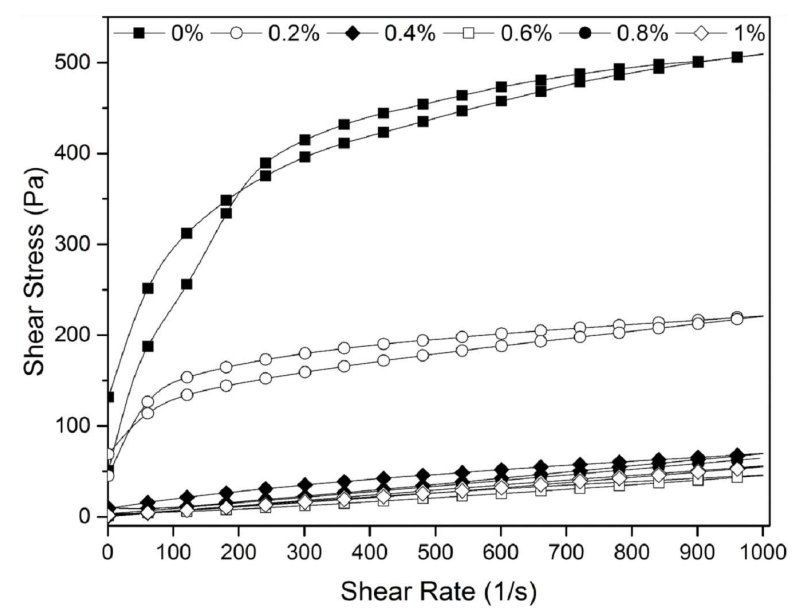

Fig. 2. The rheological flow curves of suspensions with $60 \mathrm{wt} \%$ solid loading.

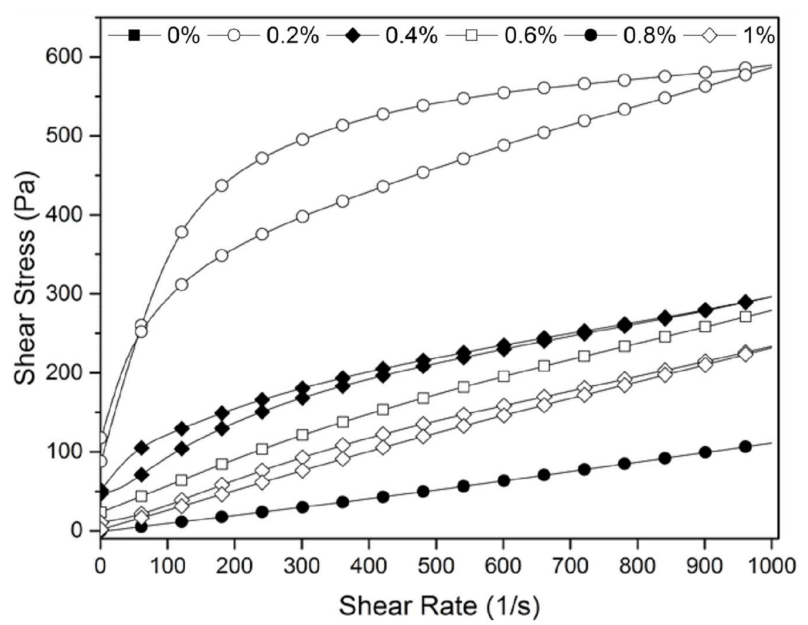

Fig. 3. The rheological flow curves of suspensions with 65 wt\% solid loading.

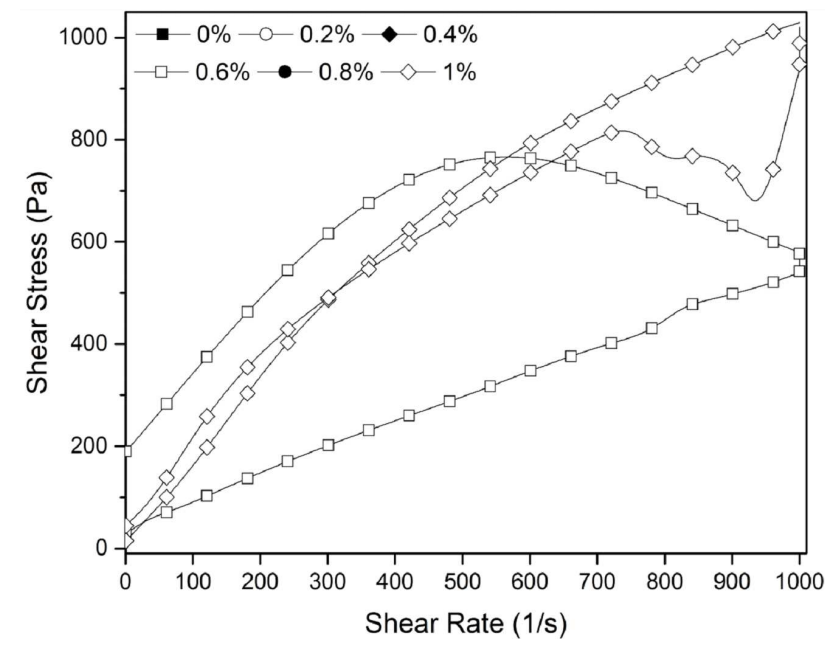

Fig. 4. The rheological flow curves of suspensions with $70 \mathrm{wt} \%$ solid loading.

For the lowest solid loading (50 wt\%, Fig. 1), flow curves indicate that the apparent viscosity of the suspensions decreases sharply as the dispersant concentration increases up to $0.4 \mathrm{wt} \%$. The proper definition of the apparent viscosity for non-Newtonian fluids is the ratio of shear stress to shear rate at any applied shear rate. A further increase in dispersant concentration continues to decrease in the apparent viscosity of the suspensions. The suspensions which include $0,0.2$, and $0.4 \mathrm{wt} \%$ Darvan 821A have thixotropic behaviour and exhibit almost non-Newtonian flow behaviour. The thixotropic behaviour of slurry is characterized generally by measuring the thixotropic loop between the ascending and descending parts of the flow curve. In descending part of the curve, the shear stress is lower due to the breaking down the bond chain through the suspension and deflocculating phenomenon.

As the solid loading is increased to $60 \mathrm{wt} \%$ (Fig. 2), the non-Newtonian flow and thixotropic behaviour is still observed at lower dispersant concentration ( 0 and $0.2 \mathrm{wt} \%$ ), however, further increase in the dispersant concentration would increase the viscosity of the suspension when compare that of solid loading with $50 \mathrm{wt} \%$. Among the five different dispersants concentration under study (60 wt\% solid), $0.6 \mathrm{wt} \%$ of dispersant which provided the lowest viscosity was the most effective dispersant amount on viscosity of the suspensions.

As the solid loading is further increased to $65 \mathrm{wt} \%$ (Fig. 3), it is seen that there is an initial decrease in the viscosity of the suspensions with an increase in Darvan $821 \mathrm{~A}$ concentration up to $0.8 \mathrm{wt} \%$. Also the data presented in Fig. 3 indicate that the viscosity of the suspensions increases with further increase in dispersant concentration. The dispersant is usually absorbed on the surface of the ceramic particle up to a critical concentration. Beyond this concentration, the dispersant would in excess remain in solution and interferes with the stabili- 
sation of the suspensions by increasing the ionic strength. Therefore, 0.8 wt\% of Darvan 821A seems to be the optimum concentration for the ceramic suspension, which gives the lowest viscosity.

As the solid loading is further increased to $70 \mathrm{wt} \%$ (Fig. 4), as can be observed, the flow behaviour greatly depends on the amount of solid loading and the effect of dispersant concentration on the maintain flow of the suspensions does not greatly influence. There are no flow behaviour suspensions with Darvan 821A concentration up to $0.8 \mathrm{wt} \%$. However, suspensions have very high slurry viscosity and highly thixotropic behaviour with 0.8 and $1 \mathrm{wt} \%$ dispersant concentration. It is well understood that the amount of liquid phase is not enough to make the suspension fluid with low viscosity in this solid loading. Low viscosity at high solid loading is an important feature of slurries for slip casting. The handling (moulding filling) is easier and high stability is provided. The lower viscosity at a given solids content, the higher the stability of the dispersed system. For the slurries of high solids content, slurry viscosity depend on the dispersant concentration.

From this point of view, suspensions with high solids loading of 65 wt $\%$ selected and among the different amounts of dispersants concentration in the range of 0.2 $1 \mathrm{wt} \%$ used for a dispersant optimization study, $0.8 \mathrm{wt} \%$ of dispersant which provided the lowest viscosity was the most effective dispersant amount on viscosity of the suspensions for $65 \mathrm{wt} \%$ solids loading.

The suspensions of PC0, PC1, PC2, PC3, PC4, and PC5 were prepared so that each solution had same solid loading levels (65 wt\%), and favourable dispersant concentration $(0.8 \mathrm{wt} \%)$, determined as a result of rheological studies on the standard composition, was added to achieve a good dispersion of ceramic particles in aqueous solution.

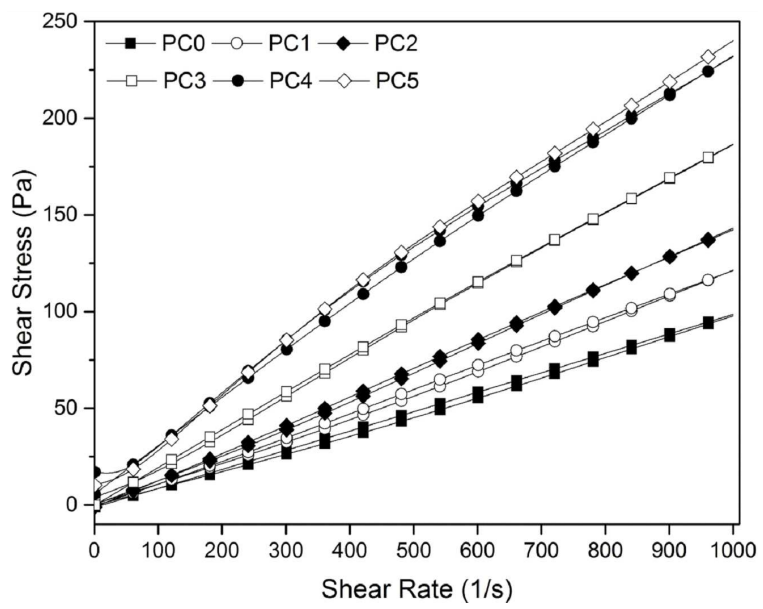

Fig. 5. The rheological flow curves of suspensions with colemanite addition for $65 \mathrm{wt} \%$ solids loading (state I).

The flow curves in Fig. 5 labelled as state I show the effect of colemanite content on the rheological behaviour of slurries with the same level of solid loading (with $65 \mathrm{wt} \%$ solid content), as shown in Table II. The shear stress values increase with increasing colemanite content in state I curve. The samples which include 0-5 wt\% colemanite exhibit almost Newtonian flow behaviour.

Solid contents of suspensions

TABLE II

\begin{tabular}{l|c|c|c|c|c|c}
\hline \hline & PC0 & PC1 & PC2 & PC3 & PC4 & PC5 \\
\hline state I & 65.00 & 65.00 & 65.00 & 65.00 & 65.00 & 65.00 \\
state II & 68.00 & 66.85 & 66.25 & 66.00 & 65.00 & 65.00
\end{tabular}

In order to obtain the same favourable rheological behaviour of slurries of different amount of colemanite additions, the solid contents of the slurries have been optimized. In Table II the optimum solid loading ratios of colemanite containing slurries are given. As the added amount of colemanite is decreased the slurries of slightly higher solid contents are needed in order to obtain acceptable and similar rheological behaviour to the slurry with $5 \mathrm{wt} \%$ colemanite addition. In Fig. 6 state II shows the flow curves of colemanite containing slurries with optimized solid contents.

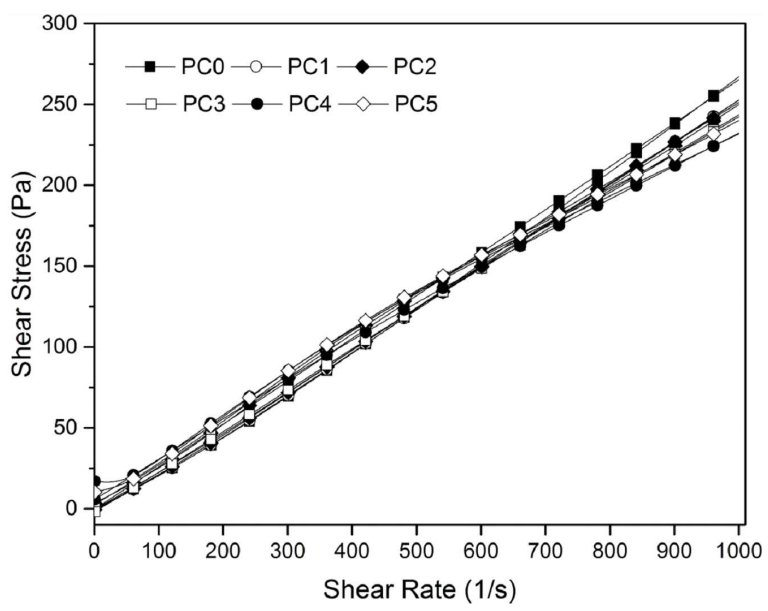

Fig. 6. The optimised rheological flow curves of suspensions with colemanite addition for optimized solids loading (state II).

\section{Conclusion}

Using dispersions of higher solid loading in preparation of ceramic green body has a very important role on the quality of the ultimate products. The higher the solid loading, the lower the liquid content of the slurry which in fact will lead to a green body of higher packing factor or higher density which also minimizes the shrinkage of green body. This is only possible if the sample at high levels of solid loading maintain its stability against sedimentation and aggregation of the particles with acceptable viscosity for easy casting.

From this point of view, suspensions with high solids loading of $65 \mathrm{wt} \%$ without calcined colemanite addition 
selected and among the different amounts of dispersants concentration in the range of $0.2-1 \mathrm{wt} \%$ used for a dispersant optimization study, $0.8 \mathrm{wt} \%$ of dispersant which provided the lowest viscosity was the most effective dispersant amount on viscosity of the suspensions for $65 \mathrm{wt} \%$ solids loading. The shear stress values and thus apparent viscosity of suspension increase with increasing colemanite content in the level of solid loading at $65 \mathrm{wt} \%$. In order to obtain the same favourable rheological behaviour of slurries of different amount of colemanite additions, the solid contents of the slurries have been optimized. As the added amount of colemanite is decreased the slurries of slightly higher solid contents (up to $68 \mathrm{wt} \%$ ) are needed in order to obtain acceptable and similar rheological behaviour to the slurry with $5 \mathrm{wt} \%$.

\section{Acknowledgments}

This research was supported by Afyon Kocatepe University Scientific Research Project (Project no: 15.MUH.10)

\section{References}

[1] D.R. Dinger, Rheology for Ceramists, Ceramic Consulting Services, 2002.
[2] A.A. Barzinjy, M.M. Zankana, Acta Phys. Pol. A 130, 239 (2016).

[3] T. Chartier, T. Rouxel, J. Eur. Ceram. Soc. 17, 299 (1997).

[4] J.M.F. Ferreira, H.M.M. Diz, J. Am. Ceram. Soc. 82, 1993 (2004).

[5] Sen Mei, Juan Yang, J.M.F. Ferreira, J. Eur. Ceram. Soc. 21, 185 (2001).

[6] E.J. Lee, Y. Iqbal, J. Eur. Ceram. Soc. 21, 2583 (2001).

[7] Y. Iqbal, E.J. Lee, J. Am. Ceram. Soc. 83, 3121 (2000).

[8] M. Davraz, Acta Phys. Pol. A 128, B-26 (2015).

[9] F. Akarslan, Acta Phys. Pol. A 128, B-403 (2015).

[10] J. Martin-Marquez, J.M. Rincon, M. Romero, J. Eur. Ceram. Soc. 30, 1599 (2010).

[11] F. Akarslan, Ö. Altinay, Acta Phys. Pol. A 128, B405 (2015).

[12] İ.H. Karahan, Acta Phys. Pol. A 128, B-432 (2015).

[13] C.. Eymir, H. Okur, Thermochim. Acta 428, 125 (2005).

[14] Ö. Yildiz, Powder Technol. 142, 7 (2004). 